
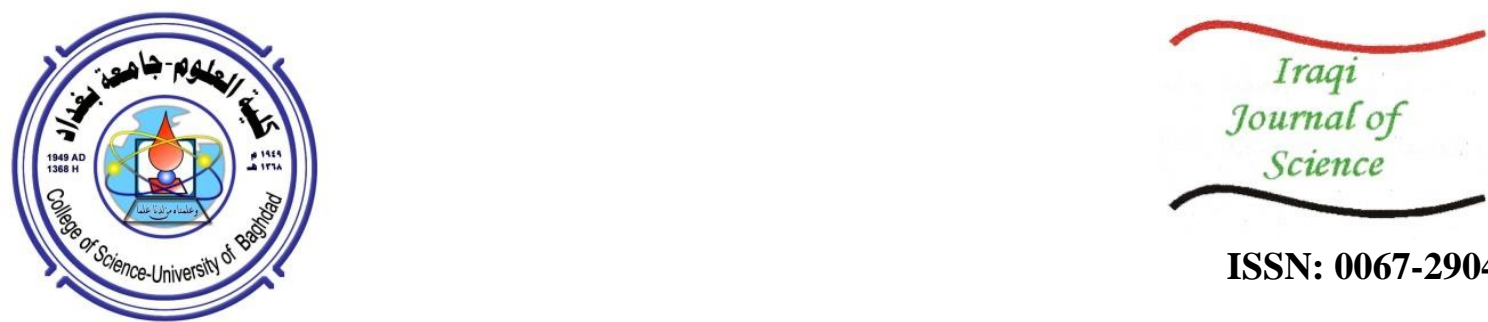

ISSN: 0067-2904

\title{
Synthesis and Characterization of Gallium Oxide Nanoparticles using Pulsed Laser Deposition
}

\author{
Mohammed M. Hameed ${ }^{* 1}$, Abdul-Majeed E. Al-Samarai ${ }^{1}$, Kadhim A. Aadim ${ }^{2}$ \\ ${ }^{1}$ Department of Physics, College of Education for Pure Science, University of Tikrit, Iraq \\ ${ }^{2}$ Department of Physics, College of Science, University of Baghdad, Iraq
}

Received: 23/10/2019 Accepted: 20/12/2019

\begin{abstract}
In this paper, the productions of gallium oxide $\left(\mathrm{Ga}_{2} \mathrm{O}_{3}\right)$ nanoparticles were achieved via using the Nd: YAG laser deposition method with a fundamental wavelength $(1064 \mathrm{~nm})$. These nanoparticles were characterized by using different methods such as X-ray diffractometer (XRD), atomic force microscopy (AFM) and Ultraviolet-visible (UV-vis) spectroscopy. To examine the effects of laser energy on the properties of nanoparticles, the experimental results and theoretical considerations were prepared by the effective method of pulse laser deposition. The synthesis of $\mathrm{Ga}_{2} \mathrm{O}_{3} \mathrm{NPs}$ ) was achieved with different ranges of energies (500 to 900 $\mathrm{mJ}$ ). Average crystallite sizes of the synthesized nanoparticles were found to be in the range of $15-37 \mathrm{~nm}$. On the other hand, the AFM images showed that the size is ranging between 60 and $85 \mathrm{~nm}$. Optical parameters of the samples showed a strong dependence on average crystallite size.
\end{abstract}

Keywords: Gallium Oxide, Nanostructure, pulse laser deposition, Structural and Optical properties

\section{تخليق وتوصيف الجسيمات النانوية لأكسيد الغاليوم المحضرة باستخدام تقنية الترسيب بالليزر النبضي

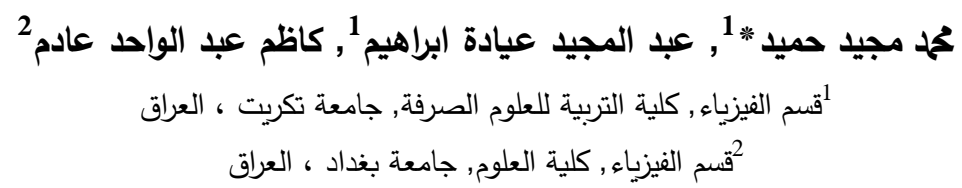

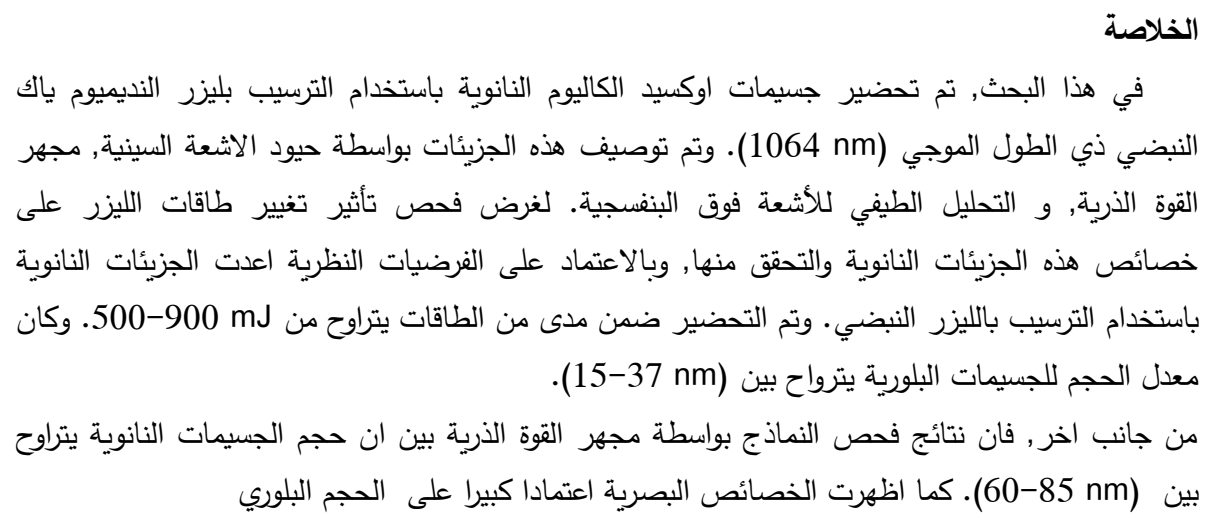




\section{Introduction}

Nanoscience is a wide area of science that studies and uses different techniques to obtain stable and new means of nanoparticles. In comparison with original and parent materials, nanoparticles become important and achieve more significance because of their remarkable physicochemical characteristic. Physical forces in the hold of nanoscale particles are included in the manual method of nanoparticles, which lead to the formation of large, stable and well-defined nanostructures. This method involves basic techniques such as vapor condensation, physical fragmentation, amorphous crystallization and many others [1]. There is an important role of metal oxide nanostructures and they have responsibility in several areas of chemistry, physics and materials science. Several applications are allowed and enabled by the different and significant properties of oxides in the production of circuits of microelectronic, devices of piezoelectric, fuel cells, sensors, coatings against corrosion and as catalysts (some catalysts have an active phase of oxide) [2]. Gallium oxide is considered as a wide band-gap semiconductor which has significant physical properties that are important for photocatalysts, gas sensors, ultraviolet photodetectors, and power devices [3]. These properties can be combined, which allows $\mathrm{Ga}_{2} \mathrm{O}_{3}$ thin films to be used in different applications, such as gas sensors, solar cells, deep-UV photo detectors, spintronics and field-effect transistors. Different techniques and methods can be used to prepare $\mathrm{Ga}_{2} \mathrm{O}_{3}$ films; for instance, electron beam evaporation, magnetron sputtering, molecular beam epitaxy, metal-organic chemical vapor deposition (MOCVD), sol-gel process, pulsed laser deposition and vapor phase epitaxy. In recent years, the huge potential of $\mathrm{Ga}_{2} \mathrm{O}_{3}$ power devices for future high-power and high-voltage applications have been illustrated by the important progress made in $\mathrm{Ga}_{2} \mathrm{O}_{3}$ transistors and diodes [4]. Numerous different polymorphs can be created from $\mathrm{Ga}_{2} \mathrm{O}_{3}$, which are designated as $\alpha-, \beta-, \gamma-, \delta$-, and $\varepsilon-\mathrm{Ga}_{2} \mathrm{O}_{3} . \beta-\mathrm{Ga}_{2} \mathrm{O}_{3}$ has a monoclinic structure and belongs to the space group $\mathrm{C} 2 / \mathrm{m} \mathrm{[5].}$

The $\mathrm{Ga}_{2} \mathrm{O}_{3}$ material is a semiconductor material with a wide bandgap (4.3-5.0 eV) [3]. The main type of gallium oxide is the $\beta$-form. This is the most popular and well established gallium oxide polymorph. Through the whole temperature range till the melting point, $\beta-\mathrm{Ga}_{2} \mathrm{O}_{3}$ is the only stable polymorph, while the other polymorphs at temperatures above $750-900{ }^{\circ} \mathrm{C}$ can be transformed into the $\beta-\mathrm{Ga}_{2} \mathrm{O}_{3}$ because they are metastable [6]. It is possible to produce and create giant single crystals and films with epitaxia by high temperature processes, including melt crystallization and vapor epitaxy, because of the thermal stability of $\beta-\mathrm{Ga}_{2} \mathrm{O}_{3}$. Due to the availability and remarkable properties of $\beta$ $\mathrm{Ga}_{2} \mathrm{O}_{3}$, it has become more interesting among other polymorphs of $\mathrm{Ga}_{2} \mathrm{O}_{3}$ and many studies were conducted about its applications. In comparison with other $\mathrm{Ga}_{2} \mathrm{O}_{3}$ polymorphs, $\beta-\mathrm{Ga}_{2} \mathrm{O}_{3}$ is well characterized, while many variations still exist in published material property data [6,7]. The aim of this study is to investigate the effects of changing laser energies on the structural and physical properties of the film precipitation.

\section{Materials and methods}

In this project, gallium oxide powder was purchased from Sigma-Aldrich with a purity of $99.9 \%$. The powder was pressed and transformed to pellets with $0.2 \mathrm{~cm}$ thickness and $1.5 \mathrm{~cm}$ diameter. Hydraulic piston (type SPECAC) was used for $15 \mathrm{~min}$ at a pressure of 6 tons. Glass substrates $(2.5 \times 7.5 \mathrm{~cm})$ were used to deposit the films of gallium oxide. Distilled water was used to clean these glass substrates and remove the remaining dust and grime from their surface. Then, glass substrates were cleaned in alcohol for $15 \mathrm{~min}$ by an ultrasonic system to remove some oxides and grease. The air of plowing was used in this process to dry these glass substrates. Finally, soft paper was used to wipe the slides and Nd: YAG laser was applied to deposit films at room temperature utilizing pulse laser deposition (PLD) technique at a wavelength of $\lambda=1064 \mathrm{~nm}$ and energy from 500 to $900 \mathrm{~mJ}$. The frequency of repetition was $6 \mathrm{~Hz}$ for 200 shots which occurred on the target surface at an angle of $45^{\circ}$. The distance between laser and target is $10 \mathrm{~cm}$, under vacuum and a pressure of $2.5 \times 10^{-2}$ mbar. The most interesting method for deposition of metals and semiconductors is pulse laser deposition (PLD). DC magnetron sputtering provides the ability to rapidly deposit huge amounts of materials, delivering high levels of deposition and good coverage. Determination of the optimal location for the target range was achieved on the surface holder.

The evaluation of the structural, optical and electrical characteristics of the thin films was performed by using different characterization techniques. Measurement of optical interference fringes can be a quick, accurate, and non-destructive approach which can be used to determine the film thickness. This method uses the laser He-Ne of $632 \mathrm{~nm}$, at $45^{\circ}$ angle of incidence, to calculate the 
thickness of $\mathrm{Ga}_{2} \mathrm{O}_{3}$ thin films. This approach depends on the laser beam interference reflected from the thin film surface and then substrates. The film thickness was determined using the following equation [8]:

$$
\mathrm{t}=\frac{\lambda}{2} \frac{\Delta \chi}{\chi}
$$

$\mathrm{X}$-ray diffraction (XRD) is considered as one of the preferred and effective methods for this objective of the qualitative and quantitative evaluation of crystalline compounds. This experimental method has long been used to quantify and establish the overall structure of thin $\mathrm{Ga}_{2} \mathrm{O}_{3}$ films, including lattice constants, grain size recognition of unknown materials, single crystal orientation, and polycrystals orientation. In this research, X-ray diffraction XRD with $\mathrm{Cu}-\mathrm{K} \alpha \mathrm{X}$-ray tube $(\lambda=1.54056)$ was used to analyze thin films. The X-ray scans were performed between $2 \theta$ XRD values at a scanning frequency of $0.08333^{\circ} \mathrm{s}^{-1}$ with a diffraction angle of $2 \theta$ and a distance of $20^{\circ}-80^{\circ}$.

Micrographs (Digital Instruments, CSPM-AA3000) of the Atomic Force Microscopy (AFM) were used to analyze the surface roughness and topography of the coated thin films.

UV companion SP-8001 double beam spectrophotometer, purchased from Metertech Corporation (Taipei, Taiwan) and covering a wavelength range of 190-1100 nm was employed. This system was used to prepare $\mathrm{Ga}_{2} \mathrm{O}_{3}$ thin films and achieve the optical measurements. There was a blank glass slide in one direction of the beam during the scanning, while another glass slide with the film deposit was put in the direction of the other beam. The films deposited on the glass slide substrates can lead to the spectrum of absorption displayed by the double beam spectrophotometer of the UV mate SP-8001.

\section{Results and discussion}

\subsection{XRD) analysis of structural properties}

Figure-1 below describes the XRD patterns of the PLD of $\mathrm{Ga}_{2} \mathrm{O}_{3}$ thin films. The diffraction peaks are indexed by comparing the data with JCPDS card files No.96-200-4988. Diffraction patterns revealed that thin films are strongly oriented along the (111) plane with favored orientation to the caxis and monoclinic crystal structures. There were also low intensity peaks corresponding to planes (401) and $\left(31-1^{-}\right)$. Also, all intensities could be increased by increasing energy deposition. Bragg's law equation was used to estimate the spacing $d$ of the lattice, as shown below [9]:

$$
\mathrm{d}=\frac{\mathrm{n} \lambda}{2 \sin \theta}
$$

where $n$ is the diffraction order which is taken as $1, \lambda$ is the $X$-ray wavelength used $(0.154056 \mathrm{~nm})$ for $\mathrm{Cu} \mathrm{K \alpha}$ target, and $\theta$ is Bragg peak diffraction angle (002). Lattice spacing $\mathrm{d}$ was calculated by the following relationship for the monoclinic lattice [10]:

$$
\frac{1}{\mathrm{~d}^{2}}=\frac{1}{\sin ^{2} \beta}\left(\frac{\mathrm{h}^{2}}{\mathrm{a}^{2}}+\frac{\mathrm{k}^{2} \sin ^{2} \beta}{\mathrm{b}^{2}}+\frac{\mathrm{l}^{2}}{\mathrm{c}^{2}}-\frac{2 \mathrm{hl} \cos \theta \beta}{\mathrm{ac}}\right)
$$

where $h, k$ and $l$ are the plane's Miller indices, while the lattice constant monoclinic unit cell was represented by a and $\mathrm{c}$. The constants of the lattices a and $\mathrm{c}$ were determined using equation (3). 


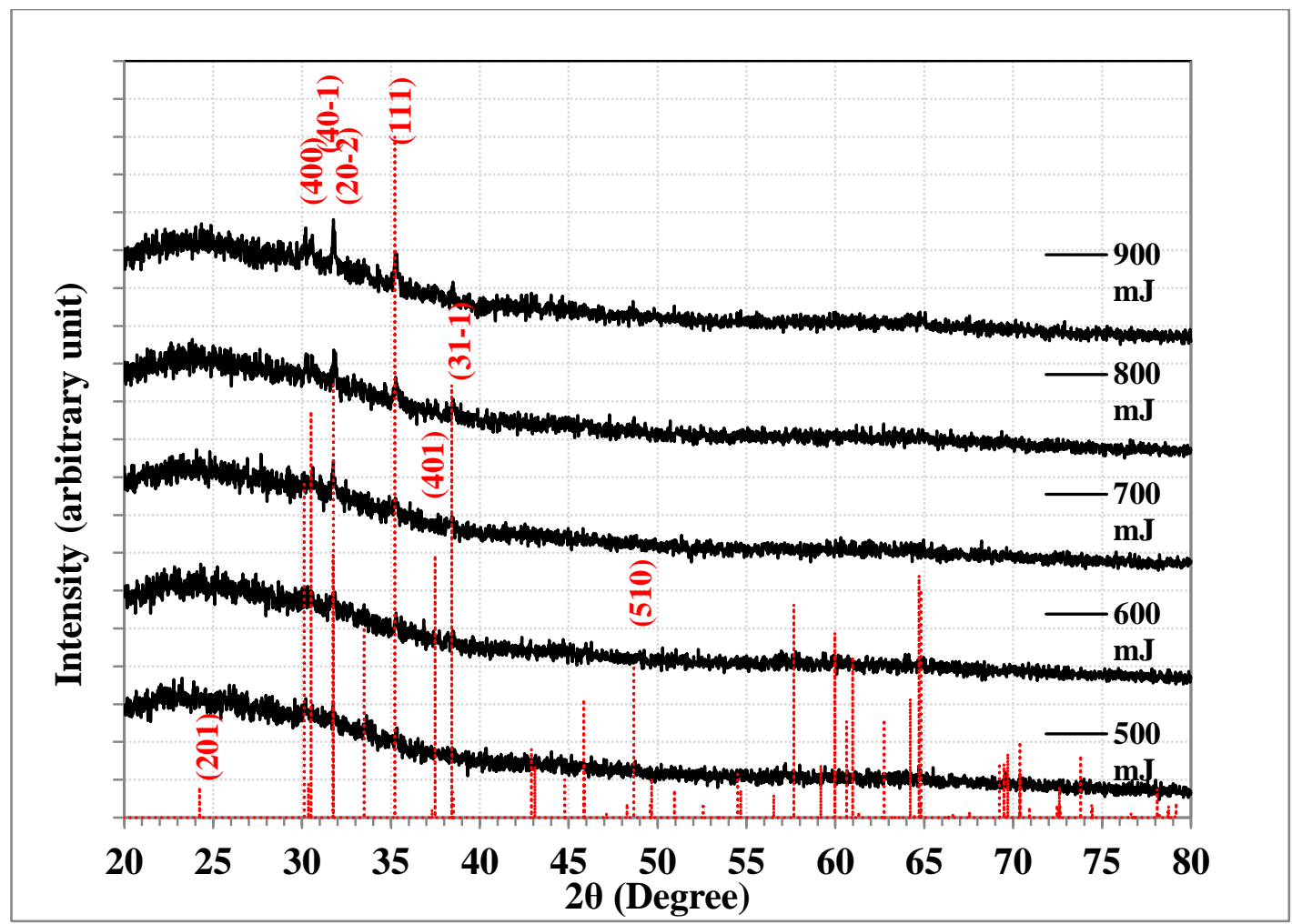

Figure 1-X-ray pattern of the PLD of $\mathrm{Ga}_{2} \mathrm{O}_{3}$ thin films.

The crystallites deficiency could attribute intrinsic stress during the growth. The intrinsic stress in the thin films can be caused by the deposition parameters such as growth temperature, gas pressure, laser power and pulse duration [9]. The negative sign with the stress value represents the inherent stress of the compression. The increasing in the thickness of film can lead to increase the stress. The energy of dislocation is inversely proportional with the film thickness, which means if the energy of dislocation is high the thickness of film is low. The increasing of the film thickness can lead to elevation of the density of dislocation and the stacking fault probabilities, thus the thin films stress was increased. Scherrer equation with XRD data was used to calculate the crystallite size (1) [11]:

$$
\mathrm{l}=\frac{0.9 \lambda}{\beta \cos \theta}
$$

where the full width at half maximum of the peak is represented by $\beta$. There was an improvement in the structural properties resulting from decreasing the size of the crystallite to increase thin film thickness.

\subsection{Surface morphology and roughness}

A photograph of $\mathrm{Ga}_{2} \mathrm{O}_{3}$ film was produced by atomic force microscopy (AFM) and showed a diameter of 2 inch, as shown in Figure- 2. The film had a strong granular surface consisting of an irregular grain agglomeration of tens of nanometers. Root mean squared roughness $\left(\mathrm{R}_{\mathrm{RMS}}\right)$ for $\mathrm{Ga}_{2} \mathrm{O}_{3}$ thin films was $7.5 \mathrm{~nm}$ (Average of Three $1 \mathrm{~mm} 1 \mathrm{~mm}$ ) near other observed values (3 to $8 \mathrm{~nm}$ ) [12,13]. 

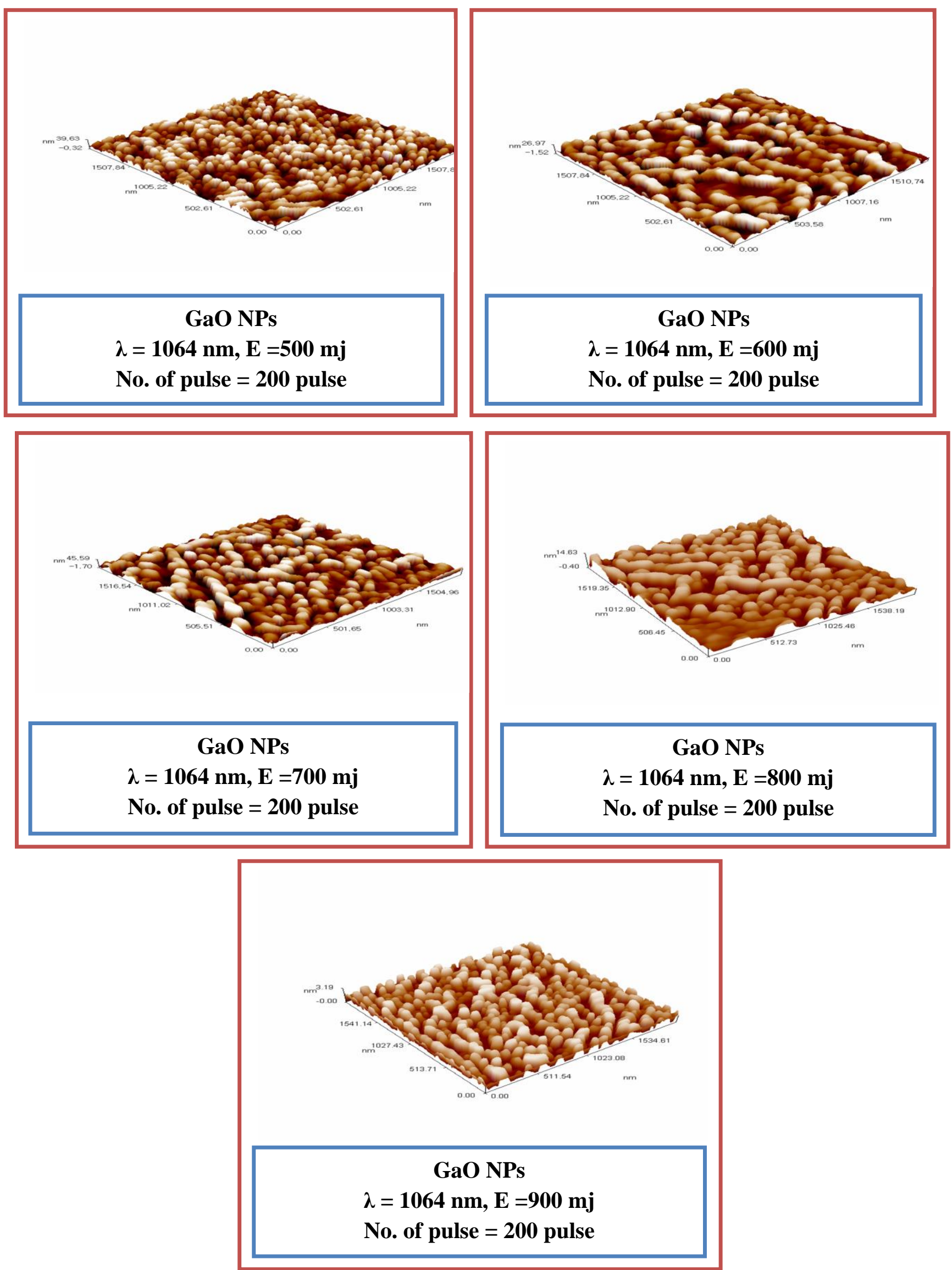

Figure 2- Images for surface morphology of $\mathrm{Ga}_{2} \mathrm{O}_{3}$ thin films analyzed by AFM at room temperature. 


\subsection{Electrical properties and optical measurements}

In general, the nominally undoped $\mathrm{Ga}_{2} \mathrm{O}_{3}$ is extremely resistive due to the WBG [14, 15]. Deviations from oxygen stoichiometry, particularly oxygen vacancies, are invoked to explain the relatively high conductivity of n-type observed in certain nominally undoped $\mathrm{Ga}_{2} \mathrm{O}_{3}$ bulk crystals and thin films. This theory seems to be controversial, however, as hybrid functional density calculations indicate that oxygen vacancy is a deep donor with ionizing energy greater than $1 \mathrm{eV}$ [16].

Because of the significance of $\mathrm{Ga}_{2} \mathrm{O}_{3}$ electrical transport properties, a detailed study of these properties was performed.

Figure 3-a shows the optical transmittance versus wavelength values of the thin films. The curves display a well-defined fringe pattern of interference, showing the thin films' smooth surface. The optical absorbance that was studied in the wavelength range between 190 to $1100 \mathrm{~nm}$ is illustrated in Figure- 3-b.
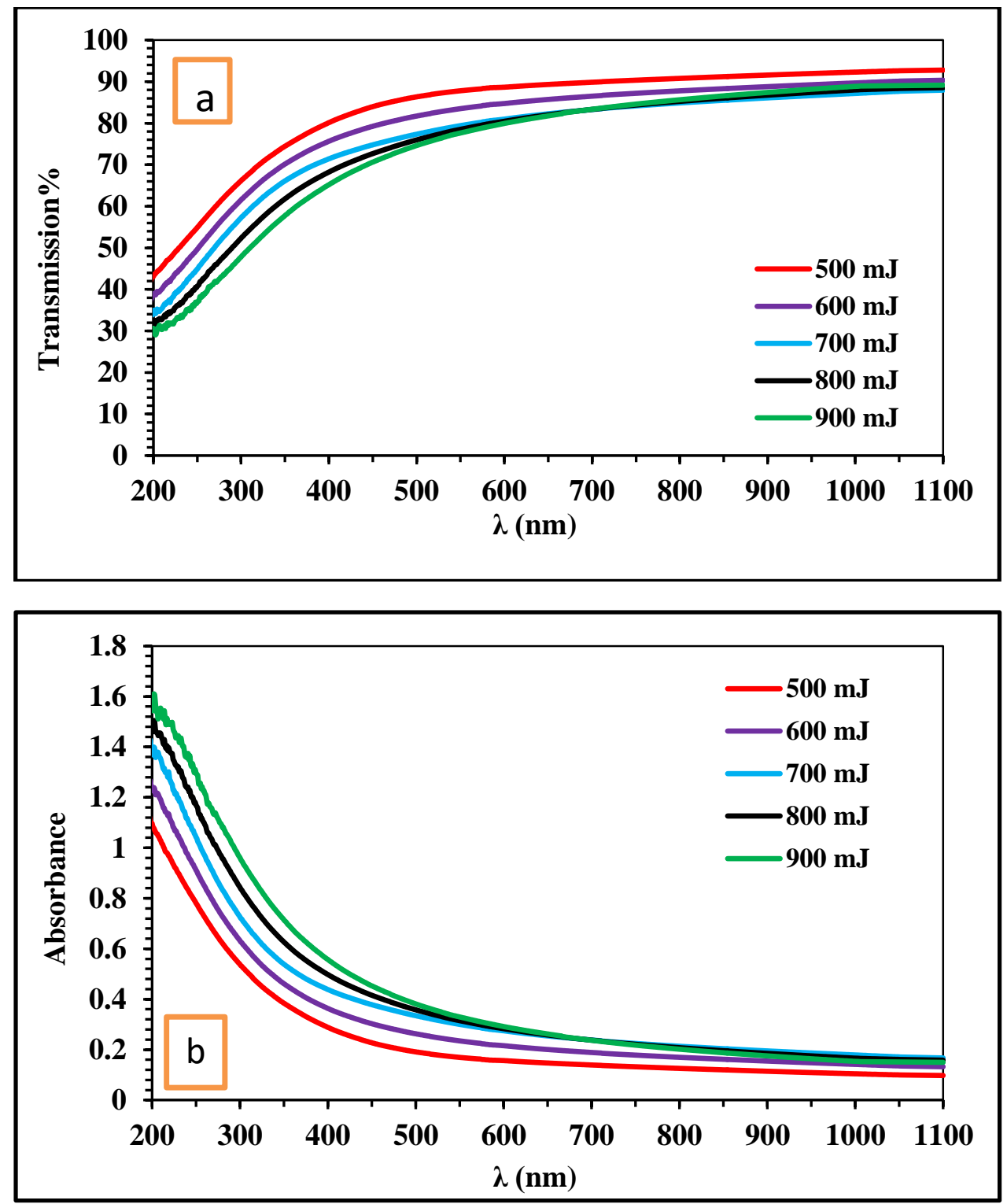

Figure 3-a and b: The optical transmittance and absorbance, respectively, of $\mathrm{Ga}_{2} \mathrm{O}_{3}$ thin films

As the aspect ratio of crystallites varies with the thickness, the optical reflection can be changed due to the morphological difference in films. The optical absorbance in the wavelength range of 450 $800 \mathrm{~nm}$ ranged from $0 \%$ to $10 \%$. The absorption was higher than $90 \%$ in the UV zone. Under the 
energy band gap, the state of defects induces the absorption. The increase in the thickness of film will move the absorption edge towards longer wavelengths indicating a decrease in the band gap. Coefficient $\alpha$ can be calculated from the transmittance and absorption data, by using Lambert's formula [17]:

$$
\alpha=\frac{1}{\mathrm{t}} \ln \left[\frac{1}{\mathrm{~T}}\right]
$$

where $t$ is the thin film thickness, while the optical transmittance values are represented by T. For thin films, the optical band gap is determined using the model of Tauc and Davis as well as the model of Mott in the high absorption zone [17]:

$$
\alpha h v=D(h v-E g)^{n} \ldots
$$

where the energy of the photon is expressed as $h v$, while $E g$ is the mean of the gap of the optical band and $\mathrm{D}$ is a constant. For $\mathrm{n}=1 / 2$, the transition data provide the best linear fit in the band-edge field, which implies that the transition is of a natural course. Figure- 4 . shows the method of measuring the band gap performed by using Tauc's plot and plotting the linear region in the graph to $(\alpha h v)^{2}=0$. The linear dependence of $(\alpha h v)^{2}$ on $h v$ shows that the thin films of Ga2O3 are semi-conductors of direct transition forms. The thin film optical band gap was between $3.9 \mathrm{eV}$ and $4.4 \mathrm{eV}$. It was found that the band gap is increasing with the increase in the film's thickness.

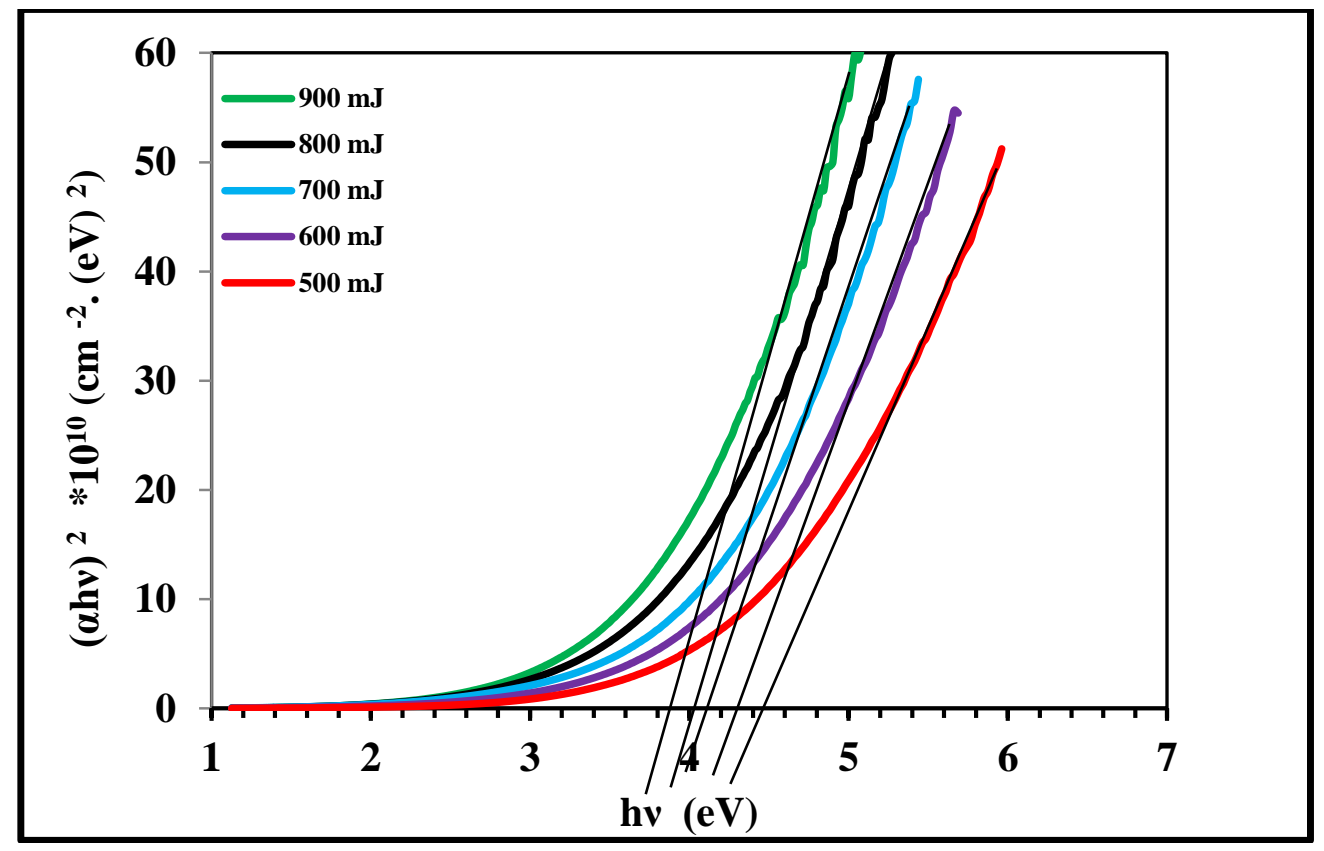

Figure 4- Energy band gap of $\mathrm{Ga}_{2} \mathrm{O}_{3}$ thin film

\section{Conclusions}

This study concluded that, as previously explained, different thicknesses of $\mathrm{Ga}_{2} \mathrm{O}_{3}$ thin films were deposited successfully on glass substrates. The deposited thin films were of single phases along the caxis with the superior rise thin (111) plane. A compressive stress was generated due to the deposition parameters, such as growth temperature, gas pressure, laser energy and pulse period. The grains were grown uniformly on the film surface that was accurately described from AFM images in the surface topography study. Despite low average values and rams roughness, the texture of thin films is relatively smooth. The deposited thin films confirmed remarkable optical properties, including very high optical transmittance in the visible zone, low optical reflection, and a roughly sharp edge of absorption at all wavelengths. As shown above, the band gap could be efficiently reduced by $\mathrm{Ga}_{2} \mathrm{O}_{3}$. This study clearly showed high electrical conductivities in the thin films. 


\section{References}

1. Rossi, M., Cubadda, F., Dini, L., Terranova, M. L., Aureli, F., Sorbo, A. and Passeri, D. 2014. Scientific basis of nanotechnology, implications for the food sector and future trends. Trends in Food Science \& Technology, 40(2): 127-148.

2. Dey, Ananya. 2018. "Semiconductor metal oxide gas sensors: A review." Materials Science and Engineering: B 229: 206-217.

3. Po-Wei Chen, Shiau-Yuan Huang, Chao-Chun Wang, Shuo-Huang Yuan, Dong-Sing Wuu, Influence of oxygen on sputtering of aluminum-gallium oxide films for deep-ultraviolet detector applications, Journal of Alloys and Compounds, 791(2019): 1213e1219.

4. Guo, D.Y. Wu, Z.P. Li, P.G. An, Y.H. Liu, H. Guo, X.C. Yan, H. Wang, G.F. Sun,C.L. Li, L.H. Tang,W.H. 2014. Fabrication of b-Ga2O3 thin films and solar-blind photodetectors by laser MBE technology, Opt. Mater. Express, 4 (2014): 1067e1076. https://doi.org/10.1364/OME.4.001067.

5. W.Y. Kong, G.A. Wu, K.Y. Wang, T.F. Zhang, Y.F. Zou, D.D. Wang, L.B. Luo, Graphene-bGa2O3 heterojunction for highly sensitive deep UV photodetector application, Adv. Mater. 28 (2016): 10725e10731.https://doi.org/10.1002/ adma.201604049.

6. Lee, S. D., Ito, Y., Kaneko, K. and Fujita, S. 2015. Enhanced thermal stability of alpha gallium oxide films supported by aluminum doping. Japanese Journal of Applied Physics, 54(3): 030301.

7. Stepanov, S.I., Nikolaev, V.I., Bougrov, V.E. and Romanov, A.E. 2016. GALLIUM OXIDE: PROPERTIES AND Applications, Rev. Adv. Mater. Sci. 44(2016): 63-86.

8. Mortezaali, A., Taheri, O. and Hosseini, Z. S. 2016. Thickness effect of nanostructured ZnO thin films prepared by spray method on structural, morphological and optical properties. Microelectronic Engineering, 151: 19-23.

9. Kaur, Gurpreet, AnirbanMitra, and Yadav, K.L. 2015. "Pulsed laser deposited Al-doped ZnO thin films for optical applications." Progress in Natural Science: Materials International, 25(1): 12-21.

10. Aly, K. A., Khalil, N. M., Algamal, Y. and Saleem, Q. M. 2017. Estimation of lattice strain for zirconia nano-particles based on Williamson-Hall analysis. Materials Chemistry and Physics, 193: 182-188.

11. Meva, F. E. A., Ntoumba, A. A., Kedi, P. B. E., Tchoumbi, E., Schmitz, A., Schmolke, L. and Lehman, L. G. 2019. Silver and palladium nanoparticles produced using a plant extract as reducing agent, stabilized with an ionic liquid: sizing by X-ray powder diffraction and dynamic light scattering. Journal of Materials Research and Technology, (2019), 1-10.

12. Goyal, A., Yadav, B.S., Thakur, O.P., Kapoor, A.K. and Muralidharan, R. 2014. Effect of annealing on b-Ga2O3 film grown by pulsed laser deposition technique, J. Alloys Compd. 583: $214 \mathrm{e} 219$.

13. Chikoidze, E., Fellous, A., Perez-Tomas, A., Sauthier, G., Tchelidze, T., Ton-That, C. and Berini, B. 2017. P-type $\beta$-gallium oxide: a new perspective for power and optoelectronic devices. Materials Today Physics, 3: 118-126.

14. Stepanov, S.I., Nikolaev, V.I., Bourgov, V.E. and Romanov, A.E. 2016. Gallium Oxide: properties and applications e a review, Rev. Adv. Mater. Sci. 44: 63.

15. Grundmann, M., Klufel, F., Karsthof, R., Schlupp, P., Schein, F.-L., Splith, D., Yang, C., Bitter, S., von H. 2016. Wenckstern, Oxide bipolar electronics: materials, devices and circuits, J. Phys. D. Appl. Phys. 49: 213001.

16. Wang, Z., Nayak, P.K., Caraveo-Frescas, J.A. and Husam N. 2016. Alshareef, recent developments in p-type oxide semiconductor materials and devices, Adv. Mater, 28: 3831e3892.

17. Gurpreet Kaurn, AnirbanMitra, K.L.Yadav, Pulsed laser deposited Al-doped $\mathrm{ZnO}$ thin films for optical applications, Progress in Natural Science: Materials International, 25(2015): 12-21. 